\title{
Ruptura diafragmática postraumática en pediatría. A propósito de un caso
}

Post traumatic diaphragmatic rupture in children. Case report

\author{
Dra. Luciana Lerendegui, ${ }^{a}$ Dr. Luis A. Gauto, ${ }^{b}$ Dra. Jimena S. Esnaola, ${ }^{a}$ Dra. Julia Udaquiola, ${ }^{a}$ \\ Dr. Roberto L. Vagni, ${ }^{a}$ Dr. Pablo Lobos, ${ }^{a}$ Dr. Juan M. Moldes Larribas ${ }^{a}$ y Dr. Daniel H. Liberto ${ }^{a}$
}

\section{RESUMEN}

La ruptura diafragmática es una entidad relativamente infrecuente en pediatría que se puede presentar como consecuencia de un traumatismo de alto impacto. Solo entre el $25 \%$ y el $50 \%$ de los casos es detectado en la evaluación inicial del paciente, lo que aumenta el riesgo de complicaciones.

En este trabajo, se presenta el caso de una paciente asintomática, de 8 años de edad, que, tras un accidente vehicular y la evaluación inicial en otro centro, fue derivada a nuestra Institución para el control evolutivo. A las 36 horas del ingreso, presentó hipoventilación pulmonar izquierda. La tomografía demostró un ascenso intratorácico del ángulo esplénico del colon y asas de intestino delgado. Se efectuó la exploración y el tratamiento quirúrgico. Los controles radiográficos diferidos no mostraron signos de recidiva.

Palabras clave: ruptura diafragmática, traumatismo múltiple, hernia diafragmática, pediatría.

\begin{abstract}
Diaphragmatic rupture is a relatively uncommon entity in pediatrics that can occur as a result of a high-impact trauma. Only between 25 and $50 \%$ of the cases are detected in the initial evaluation of the patient, which increases the risk of complications.

This paper presents the case of an asymptomatic 8-year-old patient who was referred to our institution after a vehicular accident. A day and a half after admission, a left pulmonary hypoventilation was detected. Computed tomography scan showed intrathoracic elevation of the splenic angle of the colon and the small bowel. Surgical exploration and treatment were performed. Deferred radiographic controls showed no signs of relapse.

Key words: diaphragmatic rupture, polytrauma, diaphragmatic hernia, pediatric.
\end{abstract}

http: / / dx.doi.org/10.5546/ aap.2018.e292

Cómo citar: Lerendegui L, Gauto LA, Esnaola JS, et al. Ruptura diafragmática postraumática en pediatría. A propósito de un caso. Arch Argent Pediatr 2018;116(2):e292-e295.

\section{INTRODUCCIÓN}

La ruptura diafragmática postraumática consiste en la herniación de los órganos abdominales hacia la caja torácica a través de una solución de continuidad a nivel del diafragma como consecuencia de un traumatismo de alto impacto. Se presenta en forma infrecuente, con una incidencia que varía entre menos del $1 \%$ y el $8 \%$ de los traumatismos cerrados en las distintas series. ${ }^{1-13}$ Solo entre el $25 \%$ y el $50 \%$ de los casos es detectado en la evaluación inicial del paciente, lo que aumenta el riesgo de complicaciones asociadas, tales como la oclusión intestinal o la perforación de víscera hueca, con consecuencias significativas en la evolución del paciente y alta tasa de mortalidad, que puede ascender hasta el 40\%..$^{4,5,9}$ Dado que, en la mayor parte de los casos, el mecanismo causal es un traumatismo toracoabdominal de alto impacto, otras lesiones asociadas acompañan esta entidad casi en la totalidad de los casos. ${ }^{4-7}$ Una vez hecho el diagnóstico, la resolución es siempre quirúrgica.

Se presenta un caso de ruptura diafragmática postraumática para resaltar la importancia de este diagnóstico diferencial, tanto durante la evaluación inicial del paciente politraumatizado como en el control clínico evolutivo.

\section{DESCRIPCIÓN DEL CASO}

Paciente de sexo femenino, de 8 años de edad, que sufrió un politraumatismo originado en un accidente vehicular a alta velocidad. La paciente se encontraba en la parte trasera del vehículo, con cinturón de seguridad de dos puntos. No presentó pérdida del conocimiento ni alteraciones hemodinámicas en el momento del incidente. Se derivó a nuestra Institución a las 24 h del evento, luego de una evaluación inicial en otro centro. El

\author{
Correspondencia:
Dra. Luciana Lerendegui:
luciana.lerendegui@hospitalitaliano.org.ar \\ Correspondencia:
Dra. Luciana Lerendegui:
luciana.lerendegui@hospitalitaliano.org.ar
}

Financiamiento: Ninguno.

Conflicto de intereses: Ninguno que declarar.

Aceptado: $12-10-2017$

a. Servicio de Cirugía y Urología Pediátrica.

b. Instituto Universitario.

Hospital Italiano de Buenos Aires, CABA, Argentina. 
examen físico inicial solo evidenció escoriaciones superficiales con predominio en el hemicuerpo izquierdo. La tomografía de tórax y de abdomen sin contraste, realizada en la institución de procedencia, informaba una fractura del primer arco costal izquierdo, contusión pulmonar homolateral y hematoma subcapsular esplénico.

A $1 \mathrm{momento}$ de su ingreso a nuestra Institución, la paciente estaba hemodinámicamente estable, sin requerimiento de oxígeno suplementario. Se encontraba sin sonda nasogástrica, ayunada y con un examen abdominal que no revelaba signos de alarma. Se le realizó una radiografía de tórax (Figura 1.a), en la que se observaba buena expansión en ambos campos pulmonares, con radiopacidad basal izquierda y escaso derrame pleural laminar. La ecografía abdominal mostró, como único hallazgo, el hematoma esplénico ya conocido. Sin otros datos positivos de relevancia en el examen físico, reinició la vía oral, con progresión escalonada de la dieta, tras 24 horas de observación en la Unidad de Terapia Intensiva Pediátrica (UTIP).

A las $12 \mathrm{~h}$ de reiniciada la vía oral y habiéndose decidido su pase a Sala de Cuidados Generales por buena evolución, presentó un episodio de vómito y dolor abdominal, que intercurrió luego con taquipnea y desaturación leve. Se constató, en la auscultación, una hipoventilación en el campo pulmonar izquierdo. Se tomó una nueva radiografía de tórax y se observó velamiento casi total del hemitórax izquierdo asociado a imágenes aéreas intratorácicas (Figura 1.b) y una ecografía pleural con despegamiento de $3,5 \mathrm{~cm}$ a expensas de líquido particulado. Se decidió realizar una tomografía de tórax con contraste oral, que demostró un ascenso intratorácico del ángulo esplénico del colon y asas de intestino delgado (Figura 2). Se efectuó la exploración quirúrgica por toracotomía izquierda, y se identificó una solución de continuidad en la región anterolateral del diafragma, compatible con ruptura postraumática (Figura 3). El intestino delgado se encontraba herniado, con vitalidad conservada, lo que provocó un colapso pulmonar homolateral. Luego de lograr la reducción completa del contenido, se realizó la reparación del defecto diafragmático.

La paciente se trasladó a la UTIP y se extubó a las $24 \mathrm{~h}$ del procedimiento en forma satisfactoria con evidencia radiológica de resolución de la lesión (Figura 4.a). Se otorgó el alta hospitalaria al octavo día posoperatorio. Los controles imagenológicos posteriores realizados al mes y a los tres meses no mostraron signos de recidiva (Figura 4.b).

\section{DISCUSIÓN Y CONCLUSIONES}

La hernia diafragmática postraumática es una entidad relativamente infrecuente, con una incidencia que varía desde menos del $1 \%$ hasta el $8 \%$ en algunas series cuando se refiere a un trauma cerrado y es aún menor cuando se analiza la población pediátrica en forma aislada del total de los casos. ${ }^{1-13}$ Trae aparejada una tasa de mortalidad no despreciable, que oscila entre el $6 \%$ y el $40 \%$ de los casos registrados. ${ }^{4,5,9}$ Debido

FIGURA 1.

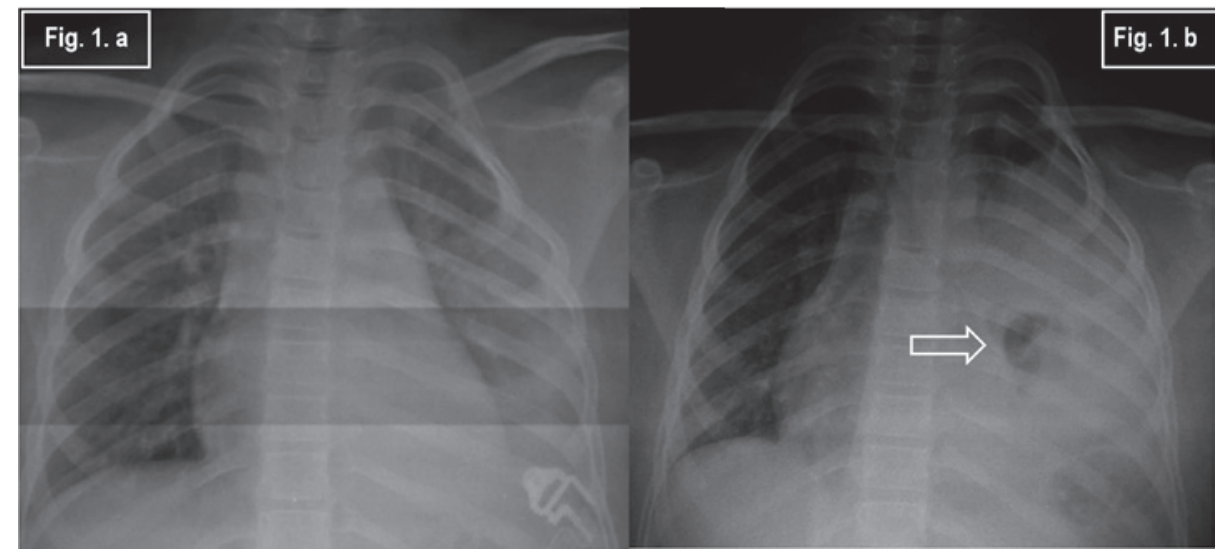

a. Radiografía de tórax al momento del ingreso. Se observa buena expansión bipulmonar. Velamiento de seno costodiafragmático izquierdo sugestivo de derrame pleural leve y contusión pulmonar conocida (concordantes con los hallazgos de la tomografía computada realizada en la institución de procedencia).

b. Radiografía de tórax a las $72 \mathrm{~h}$ del trauma. Se observa velamiento torácico izquierdo casi completo, colapso pulmonar homolateral e imágenes aéreas intratorácicas (flecha) sugerentes de herniación. 
a su baja incidencia en la edad pediátrica, el diagnóstico puede retrasarse si no se sospecha al inicio, lo que ocasiona graves complicaciones, como la oclusión intestinal y la perforación del intestino herniado.

En la mayoría de los casos, la herniación ocurre en el hemidiafragma izquierdo sin importar el mecanismo traumático. ${ }^{1,6-8}$ Se han buscado diversas explicaciones para justificar el

FiguRa 2. Tomografía de tórax con contraste oral (corte coronal).

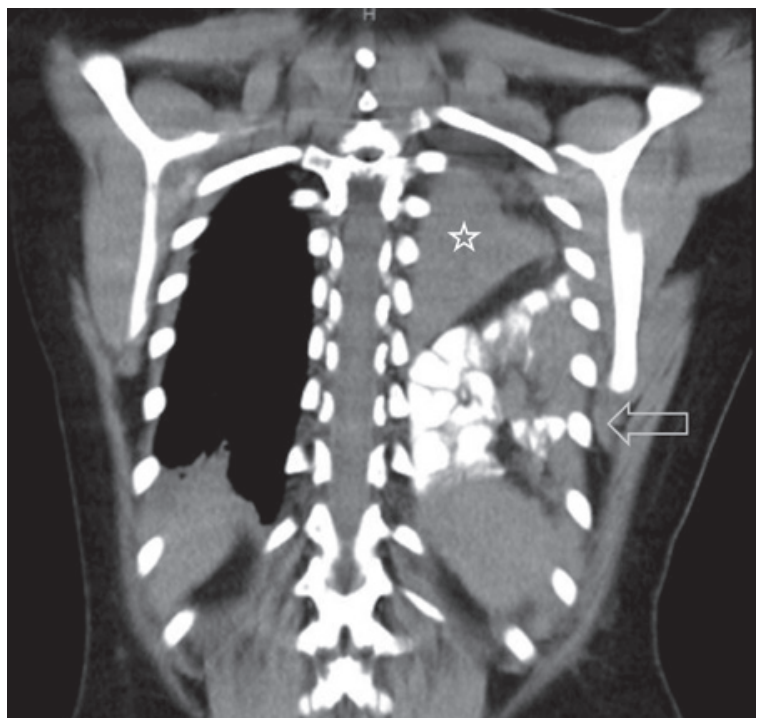

Se constata el ascenso intratorácico de asas intestinales (flecha) con colapso pulmonar homolateral (*) predominio de ruptura diafragmática izquierda. Desde el punto de vista anatómico, existe una "falta de protección" en la porción izquierda del músculo, en comparación con el lado derecho, en la que el hígado actuaría como mecanismo de barrera. Sin embargo, han sido reportados en la literatura casos de herniaciones derechas e, incluso, bilaterales. ${ }^{7,9}$ Adicionalmente, existen distintas teorías que explican por qué el diagnóstico, en general, es tardío. Una de ellas postula que el defecto diafragmático se produce en dos tiempos: un primer momento en el que el trauma inicial genera desvitalización del músculo, seguido de una segunda instancia

FIguRa 3. Defecto diafragmático (señalado por la pinza) luego de la reducción hacia el abdomen del contenido herniado. Por encima, se observa el pulmón homolateral (*)

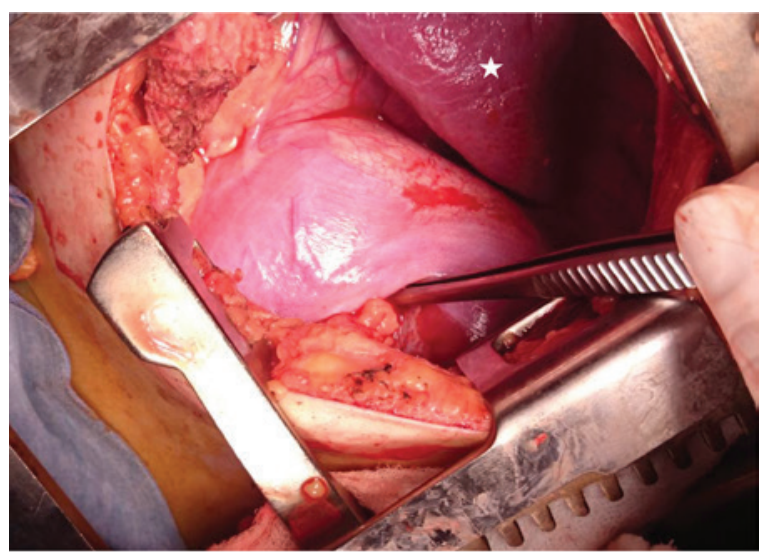

FIGURA 4.

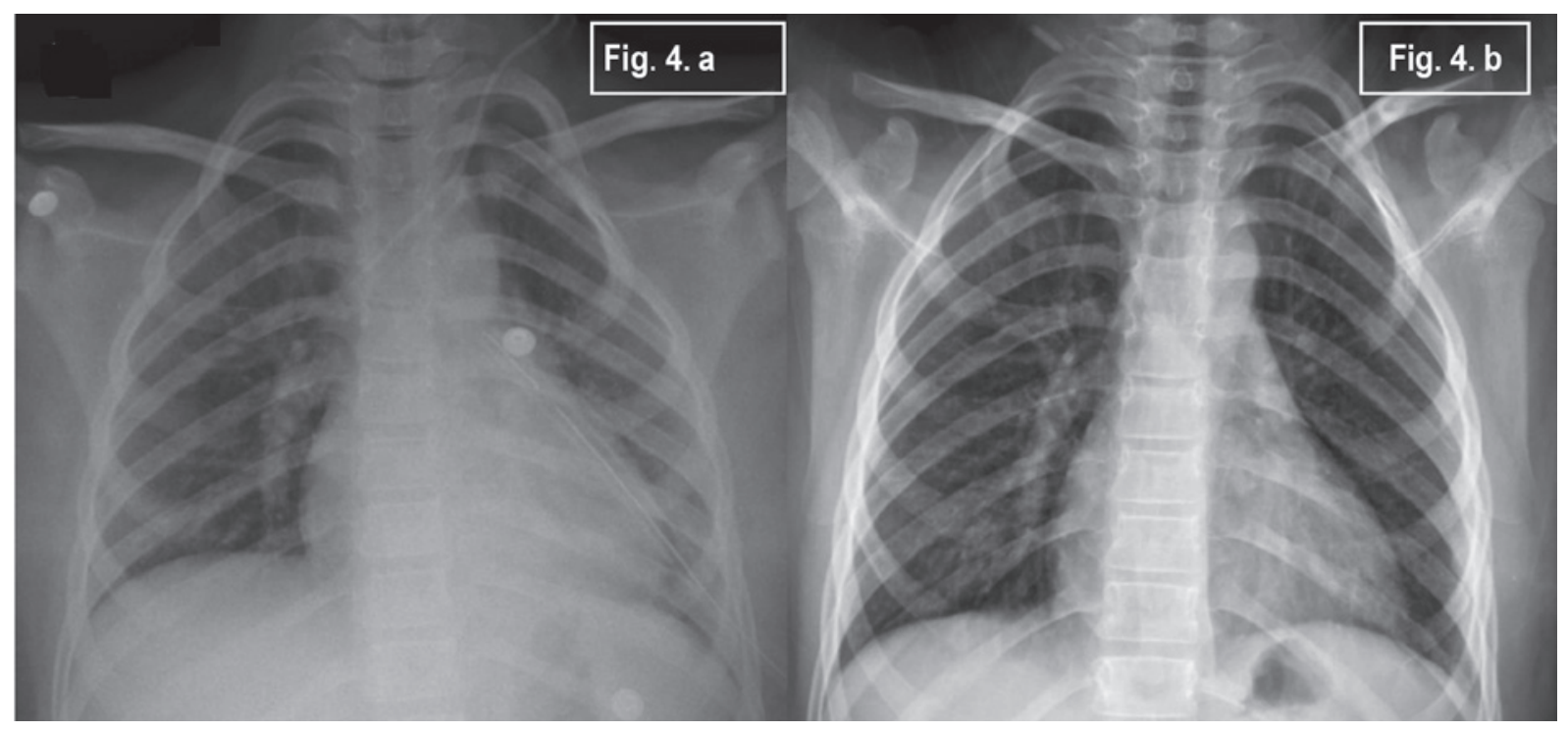

a. Control radiográfico al $4^{\circ}$ día posoperatorio.

b. Control radiográfico a los tres meses 
en la que la inflamación local termina por debilitarlo lo suficiente como para que se produzca la herniación. ${ }^{1,11}$ Otro mecanismo de lesión diafragmática que, si bien fue descrito en la población adulta, podría aplicarse también a la población pediátrica es el mencionado por Grimes. ${ }^{8}$ Este autor divide la ruptura diafragmática en tres fases: una primera fase aguda, en la que se produce la lesión, seguida de una segunda fase caracterizada por la herniación transitoria de los órganos abdominales a la cavidad torácica, en la cual hay síntomas intermitentes y no específicos. Finalmente, se produce una fase de consolidación del defecto (tercera fase), en la que se manifiestan síntomas de complicación obstructiva o sufrimiento de asa por estrangulación de las vísceras en el defecto parietal.

Son muchos los síntomas asociados a la hernia postraumática, que varían desde síntomas inespecíficos, tales como disnea y dolor abdominal, hasta aquellos directamente relacionados con la complicación del contenido herniado. ${ }^{8,11}$ Asimismo, no es atípico que la solución de continuidad se ponga en evidencia semiológicamente y por métodos complementarios de imágenes recién cuando ocurre la herniación del contenido por un aumento de la presión intraabdominal o por disminución de la presión intratorácica, como ocurre luego de la extubación. ${ }^{11}$ Han sido reportados casos en los que la herniación se hace clínicamente evidente, incluso luego de pasados meses desde el trauma. ${ }^{1}$ Además, un accidente vehicular, la causa más frecuente de una ruptura diafragmática tras un trauma cerrado, conlleva otras lesiones graves en más del $50 \%$ de los casos y puede enmascarar el cuadro de la herniación. ${ }^{9,12}$

En cuanto a los métodos de imágenes, la radiografía de tórax solo es efectiva en un 25-30\% en primera instancia para llegar a un diagnóstico certero. ${ }^{9}$ Esto se debe a que la herniación de vísceras abdominales puede ser tardía y a que, adicionalmente, puede presentarse con signos clínicos y radiológicos inespecíficos. ${ }^{2,7,11} \mathrm{La}$ tomografía cobra un rol protagónico, entonces, con buena sensibilidad y especificidad para el diagnóstico. ${ }^{13}$

La Asociación Americana de Cirugía de Trauma adopta una clasificación de las lesiones diafragmáticas en cinco grupos, en función del área muscular comprometida, que está basada en los trabajos publicados por Moore et al. ${ }^{14}$ Sin embargo, sus bases se fundamentan en la población adulta, por lo que no es por completo extrapolable a la población pediátrica, que varía significativamente en talla y circunferencia torácica de acuerdo con el rango etario.

Una vez hecho el diagnóstico, el tratamiento es quirúrgico. La cirugía, descrita tanto por abordaje abdominal como torácico, consiste en la evaluación del compromiso de las estructuras herniadas, su reintroducción en la cavidad abdominal en caso de no encontrarse signos de sufrimiento visceral, la evaluación del defecto en el diafragma y la plástica del músculo. En los casos en los que se observa un compromiso de las estructuras herniadas, deberá evaluarse la necesidad de realizar resecciones intestinales $u$ otros procedimientos adicionales para el manejo de estas complicaciones.

Se puede concluir que la ruptura diafragmática postraumática es una entidad infrecuente, pero que, de no ser detectada a tiempo, puede llevar a un deterioro abrupto de la estabilidad del paciente traumatizado. Interpretar la presentación clínica de esta patología es de crucial importancia para poder brindar al paciente un tratamiento oportuno y adecuado.

\section{REFERENCIAS}

1. Kumar KJ, Kumar MA. Delayed presentation of a traumatic diaphragmatic hernia. Indian Pediatr 2013;50(7):709-10.

2. Walchalk LR, Stanfield SC. Delayed presentation of traumatic diaphragmatic rupture. J Emerg Med 2010;39(1):21-4.

3. Cooper A, Barlow B, DiScala C, et al. Mortality and truncal injury: the pediatric perspective. J Pediatr Surg 1994;29(1):33-8.

4. Barsness KA, BensardDD, CieslaD, etal. Blunt diaphragmatic rupture in children. J Trauma 2004;56(1):80-2.

5. Shehata SM, Shabaan BS. Diaphragmatic injuries in children after blunt abdominal blunt trauma. J Pediatr Surg 2006;41(10):1727-31.

6. Alexandersson H, Riddez L. Traumatic diaphragmatic rupture (TDR) is a diagnostic challenge. Retrospective study of Swedish medical records. Lakartidningen 2014;111(1-2):32-5.

7. Al-Salem AH. Traumatic diaphragmatichernia in children. Pediatr Surg Int 2012;28(7):687-91.

8. Grimes OF. Traumatic injuries of the diaphragm. Diaphragmatic hernia. Am J Surg 1974;128(2):175-81.

9. Jain P, Kushwaha AS, Pant N, et al. Isolated posttraumatic right-sided diaphragmatichernia. Indian J Pediatr 2009;76(11):1167-8.

10. Karnak I, Senocak ME, Tanyel FC, et al. Diaphragmatic injuries in childhood. Surg Today 2001;31(1):5-11.

11. Ramos CT, Koplewitz BZ, Babyn PS, et al. What have we learned about traumatic diaphragmatichernias in children? J Pediatr Surg 2000;35(4):601-4.

12. Okur MH, Uygun I, Arslan MS, et al. Traumatic diaphragmatic rupture in children. J Pediatr Surg 2014;49(3):420-3.

13. Leung VA, Patlas MN, ReidS, et al. Imaging of a Traumatic Diaphragmatic Rupture: Evaluation of Diagnostic Accuracy at a Level 1 Trauma Center. Can Assoc Radiol J 2015;66(4):310-7.

14. Moore EE, Cogbill TH, Malangoni MA, et al. Organ Injury Scaling. Surg Clin North Am 1995;75(2):293-303. 